\title{
UNATTENDED LECTURE RECORDING: THE VIDEOAPUNTES PROJECT
}

\author{
Carlos Turró ${ }^{1}$, Jaime Busquets ${ }^{2}$ \\ ${ }^{1}$ ASIC-Universitat Politécnica de València, Camino de Vera 46021 Valencia, turro@cc.upv.es. \\ ${ }^{2}$ ASIC-Universitat Politécnica de València, Camino de Vera 46021 Valencia, busquets@asic.upv.es.
}

\section{Keywords}

e-learning, video.

\section{ABSTRACT}

Universitat Politecnica de Valencia (UPV) has developed a pilot program for automated recording of lectures called Videoapuntes during the academic year of 2012-2013. In this project we have recorded up to 36 lecture halls, from which students in the pilot courses have access to a high quality recording of the lecture comprising audio, video and the screen from the computer used by the teacher. Students access this content through the virtual campus platform. This recording has been made using the technology developed by the Opencast international consortium, in which UPV is an active member.

Results from this pilot have been very successful, both in terms of quality and the number of recordings and in terms of student feedback, with more than $85 \%$ of the students valuating this resource as helpful or very helpful. In this paper we will present the plan, the technology that we are using, and the results we have obtained from the student feedback.

\section{THE VIDEOAPUNTES' PROJECT}

In 2011, the Polytechnic University of Valencia joined international consortium Opencast [1], currently consisting of more than 30 universities interested in video resources in education, one of objectives of which is the joint development of open source software for recording lectures. This system, called Opencast Matterhorn, is a video recording equivalent of a CMS, and integrates all the features needed to manage this asset: capture, processing, indexing, and rich publishing in a corporate CMS.

Thus, a university can have a working Matterhorn system deploying capture agents in the lecture halls to record, and each of the capture agents can be used to simultaneously record audio and the screen that the teacher shows in the computer in the classroom, creating a multi-track recording, which can then be ingested and published through the core system.

We first made a pilot in the last semester of the academic year of 2011-2012 recording in nine classrooms with 15 teachers with 400 hours recorded. The production phase started in September 2012 and has continued with the installation of classrooms up to a current number of 36, with over 1,500 hours of teaching being recorded, at a peak rate of 150 hours/week.

The installation of this equipment has been designed to be as unobtrusive as possible to avoid the distraction of teachers, so we use a ceiling microphone system that does not require teachers to wear anything. And for any teacher having a session recorded is just a matter of giving that lecture in a capable lecture hall. A standard Videoapuntes classroom will cost around 3,000 euros including equipment and installation.

When a teacher wants his/her lectures to be recorded, he fills a reservation through the university CMS. Then that recording is scheduled for capture from the central services and the recording starts and stops automatically. The next step of encoding and uploading to the Sakai CMS is done automatically through the Matterhorn system.

Once the recording is uploaded to the CMS, the teacher has four days to review it, trim the beginning and the end, if necessary, and publish it using a web tool that is also available. Finally, the recording appears under the resources section on the course site. 
Students access the content using a multistream player developed by UPV called Paella Engage Player. This player is an open source HTML5 player that incorporates features for teachers as selecting different viewpoints, slide navigation, cutting videos, choosing to make public the video, etc.

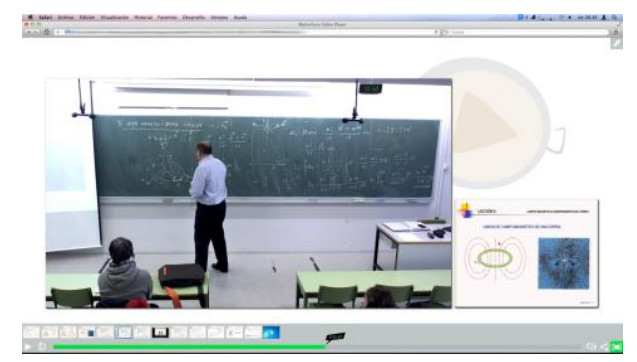

Figure 1. Paella Engage Player

\section{RESULTS}

In this academic year, more than 1,200 students have been able to see recordings from their lectures. We have a survey conducted among the students about their view of the project. The results are displayed in the following table.

\begin{tabular}{|l|l|l|l|}
\hline Question & Yes & Maybe & No \\
\hline I have found Videoapuntes' recordings useful for LEARNING & $73 \%$ & $19 \%$ & $8 \%$ \\
\hline I have found Videoapuntes' recordings useful for PASSING & $47 \%$ & $44 \%$ & $9 \%$ \\
\hline I would like to have Videoapuntes in more courses & $88 \%$ & $8 \%$ & $4 \%$ \\
\hline $\begin{array}{l}\text { Have you attended fewer lectures because of having the recordings } \\
\text { available? }\end{array}$ & $82 \%$ & $11 \%$ & $7 \%$ \\
\hline
\end{tabular}

And finally we asked about the main usage of the recordings

\begin{tabular}{|l|c|c|c|c|}
\hline & $\begin{array}{c}\text { Preparing for my } \\
\text { exams }\end{array}$ & $\begin{array}{c}\text { Review the last } \\
\text { session before } \\
\text { attending the } \\
\text { next }\end{array}$ & Solve doubts & Other \\
\hline $\begin{array}{l}\text { I have used } \\
\text { Videoapuntes for... }\end{array}$ & $39 \%$ & $27 \%$ & $65 \%$ & $8 \%$ \\
\hline
\end{tabular}

\section{CONCLUSIONS}

In this technological paper we have presented a University-wide project for automated lecture capture. Results from both the technical and the student point of view show the acceptance of this technology and its capabilities.

\section{REFERENCES}

Opencast website: http://www.opencast.org

Paella Engage Player website http://paellaengage.webs.upv.es 


\section{AUTHORS' BIOGRAPHIES}

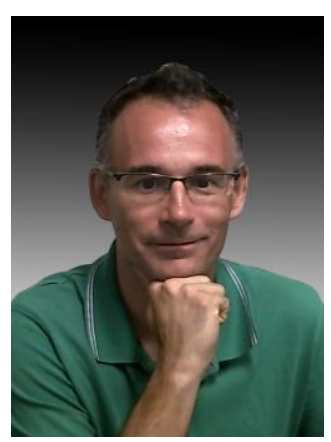

Dr. Carlos Turró is the Head of Media Services at the Universitat Politécnica de Valencia. He has published more than 50 articles in international conferences and journals. His recent work on the design and development of poliMedia for Video e-Learning has received the Spanish FICOD award and several other international awards, including being finalist for the EUNIS ETLF award. He is also working on the transLectures project for transcription and translation of video lectures

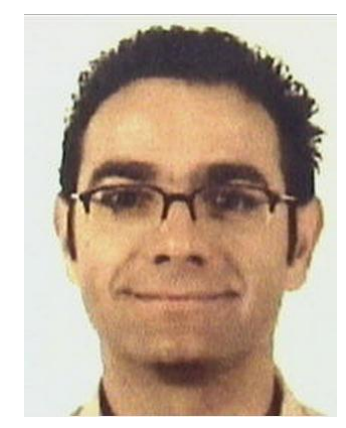

Mr. Jaime Busquets is the Head of the IT department of the Universitat Politécnica de Valencia. He is a member of the EUNIS European Learning Task Force and is currently involved in the production and deployments of Massive Online Open Courses (MOOCs) 